\title{
AFET YARDIM ÇALIŞANLARINDA SEKONDER TRAVMA
}

\author{
Ali DOĞAN ${ }^{1}$ \\ Gülseren KESKİN² \\ Ayşegül DÖNMEZ ${ }^{3}$
}

ÖZ

Kişinin yaşamında travmatik olaya maruz kalması sadece maruz kalan bireyi değil, kişinin etrafında iletişim kurduğu kişiler de etkilemesi muhtemeldir. Travma ile ilk karşı karşıya kalan (birincil) ile dolaylı olarak karşı karşıya kalan (sekonder) bireylerin travmaya gösterdikleri tepkilerde benzerlik olduğu ileri sürülmektedir. Birincil travmada tehdit olarak algılanan doğrudan olayın kendisi iken, sekonder travmatik etkide ise tehdit, iletişimde olunan bireyin travmatik olayıdır. Travmayı sekonder yaşamış kişide travmatik olayın merkezinde olan bireyin yaşantıladığı gibi tekrar yaşama, kaçınma, aşırı uyarılma belirtileri gözlemlenebilir ve rutin yaşamını idame ettirmekte güçlük çekebilir. Sekonder olay direkt olarak etkisinde kalan kişi üzerinde de en az birincil travmaya maruz kalan kişi kadar etki gösterebilmektedir. Afetlerde görev yapmakta olan yardım çalışanları sekonder travmaya maruz kalanlar arasında ön sıralarda yer almaktadırlar. Yardım çalışanlarının birtakım tedbirler alarak sekonder travmatik stresin olumsuz sonuçlarından sakınması mümkün olabilmektedir. Bu çalışmada, travmatik yaşantıya sahip kişilerde, travma sırasında ya da sonrasında müdahale eden yardım çalışanlarının uyguladığı yardım faaliyetleri neticesinde karşılaştıkları sekonder travma üzerinde durulmuştur. İkincil travmatik olayının olumsuz sonuçlarından sakınmaya yönelik girişimlerden söz edilerek, yardım çalışanlarını etkileyebilecek potansiyel sekonder travmatizasyonun önemi vurgulanmıştır.

Anahtar Kelimeler: Yardım Çalışanı, İkincil (Sekonder) Travma, Travma Sonrası Stres Bozukluğu

\section{AN ASSESSMENT IN TERMS OF SECONDARY TRAUMA OCCURRENT IN DISASTER RELIEF WORKERS}

\section{ABSTRACT}

Exposure to a traumatic event in a person's life is likely to affect not only the exposed individual, but also the people around whom the person communicates. It is suggested that there is similarity in the reactions of individuals who are first confronted with trauma (primary) and indirectly confronted with trauma (secondary or secondary). In primary trauma, the threat is the Direct event itself, while in

\footnotetext{
${ }^{1}$ Corresponding Authour/Sorumlu Yazar, Yüksek Lisans Öğrencisi, Ege Üniversitesi, Sağlık Bilimleri Enstitüsü, Afet Tıbbı AD., İzmir, Türkiye, ayayali102@gmail.com, ORCID: 0000-0001-9383-7165

2 Doç.Dr., Ege Üniversitesi, Atatürk Sağlık Hizmetleri Meslek Yüksekokulu, İzmir, Türkiye, gulseren.keskin@ege.edu.tr, ORCID: 0000-0002-5155-0948

${ }^{3}$ Prof.Dr., Ege Üniversitesi, Hemşirelik Fakültesi, İzmir, Türkiye, aysegul.donmez@ege.edu.tr, ORCID: 0000-0002$1087-9173$
} 
JPH, DECEMBER 2021, 6(3):421-432

secondary traumatic effect, the threat is the traumatic event of the individual in communication. A person who has experienced secondary trauma may experience symptoms of reliving, avoidance, over-arousal, as experienced by a person who is at the center of a traumatic event, and may have difficulty maintaining a routine life. A secondary event can have at least as much effect on a person who is directly affected by it as on a person who is subjected to primary trauma. Aid workers who serve in disasters are among those decimated by secondary trauma. It is possible for aid workers to avoid the negative consequences of secondary traumatic stress by taking a number of measures. In this study, the focus was on the secondary trauma that people with traumatic lives face as a result of the relief activities carried out by aid workers who intervene during or after the trauma. Attempts to avoid the negative consequences of a secondary traumatic event were mentioned and the importance of potential secondary traumatization, which may affect aid workers, was emphasized.

Keywords: Aid Worker, Secondary Trauma, Post Traumatic Stress Disorder

\section{GíRİş}

Günümüzün küresel anlamda önde gelen sorun alanlarından afetler, pek çok insanın yaşantısını etkilemekte, afetler sonrası yaşanan maddi ve manevi kayıplar nedeni ile bireyleri travmatik hale getirmektedir (Işıklı ve Tüzün, 2017). Afetlere maruz kalmanın etkilenen topluluklar üzerindeki olumsuz etkisini ortaya koyduğu ifade edilmiştir (Norris vd., 2002). Afet, "büyük hasara, yıkıma ve insanların acı çekmesine neden olan öngörülemeyen ve genellikle ani gelişen, yerel kapasiteyi aşan, ulusal veya uluslararası düzeyde dış yardım talebi gerektiren durumlar " olarak tanımlanmaktadır. Dünya genelinde artan afet sayısı ile birlikte çok sayıda insan etkilenmiş ve ekonomik kayıplar önemli boyutlara ulaşmıştır (Sifaki vd., 2017). Afetler, kurtarma çalışmalarına katılan kişilerin fiziksel, psikolojik ve sosyolojik sağlıkları üzerinde de zararlı bir etkiye sahiptir. Son y1llarda, travmatik olaylara dolaylı olarak maruz kalan profesyonellerin de travma sonrası stres tepkileri yaşayabileceği konusunda artan bir farkındalık vardır. İşin doğası gereği, kurtarma görevlileri her zaman ciddi şekilde yaralanmış veya cesetlerle karşılaşırlar, hayatta kalan ciddi fiziksel zarar görmüş kişilerin duygusal tepkilerine (sıkıntı, keder ve öfke) tanık olurlar, bir hayat kurtarmada başarısız olduklarında hayal kırıklığı yaşarlar ve kendilerini potansiyel fiziksel zarara maruz bırakırlar (Xiaorong vd., 2018). Tüm bu stresörler, bir felakete maruz kalmayan genel nüfusa kıyasla, kurtarıcılar arasında olumsuz psikolojik sonuçların olasılığını artırabilir (Walker vd., 2016).

Bir afet meydana geldiğinde tıbbi yardım ve acil sağlık hizmetlerinin sağlanması çok önemlidir, çünkü bu sağlık sistemleri ve sağlık çalışanları üzerinde muazzam bir yük oluşturur (Broby vd., 2018). Afet bölgelerine gönderilen kurtarma görevlilerinin bazen kurtarma 
JPH, DECEMBER 2021, 6(3):421-432

çalışmaları için yetersiz eğitim aldıkları ve üyeler arasında etkisiz ekip çalışmasıyla karşılaştıkları ve bu durumun konuşlandırma sonrasında olumsuz deneyimlere yol açtığı bildirilmektedir. Afet çalışmasının doğası gereği, kurtarıcılar, özellikle sağlık çalışanları, Akut Stres Bozukluğu (ASD), anksiyete ve depresyon, Travma Sonrası Stres Bozukluğu (TSSB) ve diğer psikolojik bozukluklar dahil olmak üzere psikolojik sorunlar açısından risk altındadır (Lee vd., 2017 ; Xiaorong vd., 2019). Son yıllarda dolaylı travmaya maruz kalmanın veya travmatik olaylar yaşayan başkalarıyla empatik etkileşimin etkisiyle gerçekleştiğine inanılmaktadır. Bu yaklaşımın ortaya koyduğu tanı, merhamet yorgunluğu, dolaylı travmatizasyon, ikincil travmatik stres gibi farklı kavramlarla açıklanmaya çalışılmaktadır (Tominaga vd., 2019). Bu travmanın kurtarma çalışanları üzerindeki olumsuz etkisi uzun süreli de olabilir. Dünya Ticaret Merkezi (WTC) 11 Eylül saldırısına afete müdahale edenlerle ilgili bir çalışma, kurtarma çalışmasının üzerinden 11-13 yıl geçmesine rağmen, kurtarıcıların sırasıyla \%9.7'sinin mevcut ve \%7.9'unun TSSB yaşadığını göstermektedir. Travmatik yaşam olayları kişilerde farklı etkiler ortaya çıkarabilmektedir. Bu etkiler, DSM-5'te (zihinsel hastalıklar için bir tanı ölçütü) istenmeyen fikirler, uzaklaşma, duygu-durum değişiklikleri ve aşırı irkilme olarak tanımlanan travmatik bozukluk belirtilerine ek olarak, kişinin kendisi ve dünya ile alakalı ana inanışlardaki kalıcı değişimleri de içerebilir (Birinci ve Erden, 2016). Bu doğrultuda sekonder travmatik olayının olumsuz sonuçlarından sakınmaya yönelik bilgilerden söz edilerek, yardım çalışanlarını etkileyebilecek potansiyelde olan sekonder travmatizasyonun önemi ile ilgili farkındalık oluşturulmalı ve önlemler alınmalıdır.

$\mathrm{Bu}$ çalışmada, travmatik yaşantıları olan kişilere, travma sırasında ya da sonrasında müdahale eden yardım çalışanlarında ortaya çıkan sekonder travma, travmada etkisi olan faktörler ve baş etme yöntemleri üzerinde durulması amaçlanmıştır.

\section{AFET-RUHSAL TRAVMA}

Afet ardından meydana gelen psikolojik travmalar kişilerin yaşamını kötü etki gösterebilme ve kişilerin ruhsal durumunu hayat boyunca sürebilecek derecede hasar vermektedir. Psiko-sosyal etkiler kişileri doğrudan veya sekonder yoldan etkilenenlerde görülebilmektedir. Buna bağlı olarak verilmesi gereken psikolojik danışmanlık verilmediğinde kişilerde farklı formlarda ruhsal problemler gözlemlenmekte ve yakınındaki kişileri etkileyip sekonder bir travmaya sebebiyet verebilmektedir (Doğan vd., 2014).

Dünya çapında savaş ve terör faaliyetleri etkisi üzerine çalışmalar dünya üzerinde olumsuz zihinsel etkiler geliştirerek kişileri doğrudan etkileyerek kişilerde ruhsal durumunda bir 
JPH, DECEMBER 2021, 6(3):421-432

takım değişikler meydana getirmektedir (Berger ve Gelkopf, 2011). Kriz hali ile birlikte ruhsal travmalarda kendini göstermektedir. Fakat kriz halinde meydana gelen travmaların etkisi ruhsal olarak, maruziyet yaşayan her kişiyi tıpatıp aynı şekilde etki göstermemektedir. Travma ardından kendini gösteren bu cevapsal haller sürekli devam edecek özellikte değildir. Fakat maruziyet ardından kendini gösteren ruhsal maruziyet, yaşamı hiç göz ardı edilemeyecek bir şekilde tehdit etmektedir. Buna ek olarak major depresyon gibi ruhsal sorunlara neden olabilmektedir (Kukuoğlu, 2018:39-52).

Afete maruziyet yaşayan kişilerin verdiği cevapları afet ardından geçen zamana göre farklı şekilde gözlemlenmektedir. Bu cevapsal farklılaşma psikolojik şok (kısa süreli ve aniden gerçekleşen ilk tepki), tepki dönemi (duygusal ve tepkisel davranışları), zihinsel olarak olanları düşünme (dış dünya ile kendini soyutlama) ve son olarak iyileşme ve yeniden uyum dönemi olmak üzere dört dönem olarak değerlendirilmektedir (Hacığlu vd.,2002).

Afet sonrası travmaya maruz kalan çalışanlar, sağlık çalışanları, sivil savunma ekipleri, itfaiye ekipleri, arama ve kurtarma timleri, güvenlik birimleri (polis, asker), adli meslek grupları (avukat,hakim vd.), basın ekipleri , öğretmenler, sosyal çalışmacılar ve terapistlerdir (Gündüz, 2020).

\section{2. İKINCİL TRAVMATİK STRES VE BELİRTILERİ}

Acil durumlar, afetler, hastalık salgınları ve çatışmalar dahil olmak üzere büyük olaylar, insanların yaşamları üzerinde birçok doğrudan etkiye sahiptir. Bu koşullarda, 'stres' yaygın olarak kullanılan bir terimdir. Bazen bir uyarana ve bazen de insanların tepkilerine atıfta bulunur. Büyük olaylar ve acil durumlarla ilgili olarak, stres, insanın psikolojik, fiziksel ve davranışsal tepkilerini ifade etmekte kullanılır (Lock vd., 2011). Stres insanları motive ettiğinde olumlu olabilir, ancak insanların yaşadığı stres seviyesi ezici ve nahoş olduğunda bir sorundur. Stresörler, insanları bir stres tepkisi yaşamaya teşvik eden veya aşırı olduğunda zorlanma veya gerilime neden olan durumlardır. Birincil stres etkenleri, "özellikle büyük olaylar, afetler ve acil durumlarda doğal olan ve doğrudan bu olaylardan kaynaklanan" faktörler olarak tanımlanırken, ikincil stres etkenleri, olayla dolaylı olarak ilişkili veya "doğal olmayan ve sonuç olarak ortaya çıkan" stres nedenleridir. İkincisinin örnekleri arasında aile ilişkilerinin bozulması vs. sayılabilir. İkincil (sekonder) travmatik stres, kişinin bir başkasının travma deneyimlerini ilk olarak algıladığında meydana gelen emosyonel (duygusal) baskıdır (Williams vd., 2021). 
JPH, DECEMBER 2021, 6(3):421-432

Amerika Birleşik Devletleri'nde her y1l 10 milyondan fazla çocuk istismar, şiddet, doğal afetler gibi stresör durumlara maruz kalmaktadır. Bu deneyimler, çocukların yaşamlarını derinden bozabilecek ve onları çocuk hizmeti veren profesyonellerle temasa geçirebilecek önemli duygusal ve davranışsal sorunlara yol açabilmektedir. Terapistler, vaka yöneticileri ve travma geçirmiş çocukların ve ailelerinin bakımıyla ilgilenen diğer yardım uzmanları için, sadece travma hikayelerinin dinlenmesi bile, onlarda yaşam kalitesini düşüren duygusal bir yük oluşturabilir. $\mathrm{Bu}$ dolaylı travmaya maruz kalmanın etkilerine ilişkin bireysel farkındalık, çalışanın sağlığını korumanın ve çocukların kendilerine yardım etmeye kararlı olanlardan sürekli olarak mümkün olan en iyi bakımı almalarını sağlamanın temel bir parçasıdır. İkincil travmatik stres terimi üzerine çalışan Figleye göre, ikincil travmatik stres, bir bireyin başından geçen duygusal olayı algılamanın neticesi şeklinde gelişen duygu ve hareketler olarak adlandırılmış ve travmaya maruziyet yaşayanlarda yardım etme veya yardımcı olma isteğinden doğan stres karşılığı şeklinde açıklanmıştır ( Figley, 1995). İkincil travmatik stresin etkileri mesleki, fiziksel ve emosyonel olarak üç ana başlıkta değerlendirilir. Mesleki belirtiler; bazı kurtarma çalışmalarında müdahaleden kaçınma, afetzede ya da yakınlarına karşı empati kurmada azalma, işe gitmede isteksizlik durumunu neden olabilmektedir. Fiziksel rahatsızlıklar; baş ağrısı, gastrolojik problemleri, kas ağrıları, uyku sorunları, mental çökkünlük ve kardiyolojik problem belirtileridir. Emosyonel sorunlar; huzurun kaçması, suçluluk duyma, korku, afetzedenin travmasını düşünme, kaygı, madde bağımlılı̆̆ı, depresyon, güven sorunları, öfke, şüphecilik, stres ile başa çıkmada güçlük, yalnızlaşma, şiddete yönelim, algı değişiklikleri ve bellekte meydana gelen problemlerdir (Stamm, 2005).

Travmatik hayata sahip kişilere destek davranışında olan meslek gruplarının, kişilerin örseleyici hayatlarıyla karşılaşmalarıyla deneyimledikleri bu belirtiler olağandışı bir hayata karşı gösterilen olağan tepkiler şeklinde tanımlanmaktadır. Ancak bu tepkiler, olağan sürenin ve şiddetin üzerine çıktığında klinik açıdan desteğe ihtiyaç duyulmaktadır. Travma Sonrası Stres Bozuklu (TSSB) 'nda da olduğu üzere, iletişimde olduğu kişinin travmatik hayatıyla karşılaşan tüm meslek gruplarında benzer travmatizasyon gözlenmeyebilir. Buna ek olarak, yaşananlar karşısında deneyimlenen güçlüklere karşı gösterilen tepkilerde de farklılıklar olabilir (Palabıyıkoğlu ve Cesur, 2013).

\section{IKINCIL TRAVMATIK STRES OLUŞUMUNUNDA ETKISİ OLAN FAKTÖRLER}

İkincil travmatizasyon, travmatize olmuş bir bireyle yakın veya yoğun temastan kaynaklanan sıkıntı ve davranış belirtilerini ifade eder. Semptomlar TSSB'ninkileri yansıtır; 
JPH, DECEMBER 2021, 6(3):421-432

ancak, doğrudan maruz kalmaktan ziyade başka bir kişinin travmasının farkındalığından üretilirler. Literatürde sekonder travmatik stresin, bireylerin travmatik olaylarla karşılaşma sayısı, yaş, cinsiyet, travmatik bir geçmişe sahip olma, başa çıkma yöntemleri, eğitim gibi değişkenlerle ilişkin farklılaştığı belirtilmektedir (Dogan vd., 2016). Birçok sağlık çalışanında travmatik bir durumla karşılaşmanın ardından bitkinlik, korku ve uyku problemleri yaşandığ 1 ve bu durumun TSSB, kaygı, depresyon ve tükenmişlik şekline dönüşebildiği belirlenmiştir (Dünya Sağlık Örgütü, 2020b). Özellikle, araştırmalar genç terapistlerin daha yüksek düzeyde sekonder travmatizasyon gösterdiğini bulmuştur. Çalışma hayatına yeni başlayanların, uzun yıllardır çalışanlara göre daha yüksek travmatik stres yaşadıkları belirlenmiştir (McCann ve Pearlman, 1990).

Literatürde sekonder travmatizasyonla ilişkilendirilen bir diğer faktör de çalışanın kişisel travma öyküsüdür. Erken bir kaybın bireylerin yaşamdaki sonraki kayıpların üstesinden gelmesini zorlaştırabileceği düşünülmektedir. Bu bağlamda geçmişte travmaya maruz kalmış sağlık çalışanları sekonder travmatizasyon yaşama riski altındadır (Figley, 1995). Travma kurbanları ile çalışan terapistler arasında yürütülen mevcut araştırmalar, terapistin geçmişte travmaya veya istismara maruz kalması ile şu anda sekonder travmatizasyonun yaşam durumları arasında pozitif ilişki bulunmuştur (Moore, 2004). Zara ve İçöz (2015) 'ün yapmış olduğu çalışmada Türkiye 'nin doğu ne güneydoğu bölgelerinde görev yapmakta olan ruh sağlığ çalışanların daha fazla sekonder travmaya maruz kaldığı bulgusu saptanmıştır (Zara ve İçöz, 2015). Ttravma geçmişi olan kişilerde sekonder travma geliştirmesi konusunda etkili bir neden olarak ortaya çıkmaktadır (Baird ve Kracen, 2006). Bir başka faktör ise stres ve sıkıntı ile başa çıkmak için kilit bir kaynak olarak ustalığa büyük önem atfetmiştir. Terapistler için profesyonelliğin önemi, temel olarak kişisel ve profesyonel yaşamları arasında sınırlar koyma yeteneğinde olduğu kadar, kendilerini dünyaları üzerinde kontrol sahibi olarak algılamalarında yatmaktadır. Bir çalışma, profesyonellik ve sekonder travmatizasyon arasında negatif bir ilişki olduğunu ortaya koymuştur (Dagan vd., 2016).

Çalışılan alan travmatik stres açısından önemlidir Özellikle çocuklarla çalışan gruplarda sekonder travmatizasyona daha fazla rastlanılmıştır. Fazla çalışma saatleri, çalışma yükü, kazazedenin çocuk olması, maruz kalınan ve dahil olunan durumun insan vasıtasıyla gerçekleşmiş olması, şiddetli fiziksel yaralanma ve ölümün olması sekonder travmaya neden olabileceği belirtilmiştir (Kahil ve Palabıyıkoğlu, 2018). Çocuk yoğun bakım ünitelerinde çalışan sağlık çalışanlarında ruhsal travma düzeyinin araştırıldığı bir çalışmada, çalışanların büyük çoğunluğunda yüksek düzeyde stres ve merhamet yorgunluğu yaşadığı sonucuna varılmıştır. Çalışanlara profesyonel destek sağlanarak stres ve merhamet yorgunluğu yaşama durumunun en alt seviyelere indirilmesi önemlidir (Meadors ve Lamson, 2008). 
JPH, DECEMBER 2021, 6(3):421-432

İkincil travmatik stresi (ITS), bunun personel üzerindeki etkilerini ve etkisinin nasıl hafifletileceğini anlamak, kurum ve kuruluş liderlerini ilgilendirir. Bazen günlük olarak travmatik ve rahatsız edici olaylara maruz kalmak kişinin kişisel ve profesyonel yaşamını etkiler. Personel, başa çıkmak için farklı yollar edinir. Bu durum personelin işlevselliğini bozar, çalışma ortamında zorluklar yaratabilir. Sekonder travmanın bireylerde tükenmişliğe yol açtığı, düşük muhakeme gücü, düşük üretkenlik, düşük iş kalitesine yol açtığı görülmüştür (Rienks, 2020).

Birinci ile Erde'in (2016) arama kurtarma çalışanları ile gerçekleştirdiği araştırmada ise, çalışanların tükenmişlik düzeylerinin ise yüksek olduğu sonucuna varılmıştır (Birinci ve Erden, 2016). TSSB ve madde kullanımı problemine sahip kişiler için hizmet veren 412 katılımcı çalşsan ile yürütülen çalışmada \%19.9'u sekonder travmatik stres sorunu ortaya çıktı̆̆ sonucuna varılmıştır (Ewer vd., 2014: 252). Buna ek olarak küresel olarak çalışılan bir başka çalş̧ada güvenlik güçlerinin, itfaiyecilerin, arama kurtarma ekiplerinin, hastane öncesi acil sağlık çalı̧̧anlarının sahip olduğu mesleği sebebiyle yüksek risk sınıfı içinde oldukları tanımlanmıştır (Carson vd., 2000: 122).

\section{4. İKINCIL TRAVMATÍK STRESLE BAȘ ETME YÖNTEMLERİ}

Baş etme adına travmatik stresin ele alınması hem bireysel hem de örgütsel düzeyde gerçekleşmelidir. Bunlar önleme ve tedavi olmak üzere iki kategoriye ayrılır. Yardımclar, bir yardım rolüyle ilgili olarak koruyucu olabilecek güçlü uygulama yaklaşımlarını ve kişisel sınırları sürdürmelerine yardımcı olan yaşam tarzı ve çalışma alışkanlıklarını benimseyebilir. Bazen en deneyimli ve kişisel olarak uyumlu profesyoneller bile kendilerini sekonder travmatizasyonla mücadele ederken bulabilirler (Bell vd., 2003).

Literatürdeki bir başka çalışmanın bulgularında ise Whitfield ile Kanter (2014) travmatik yaşantıya sahip kişilerle beraber çalışan meslek arkadaşlarının travmaya maruz kalma düzeylerini düşürmenin mümkün olabileceği şeklinde bulgular ortaya koymuştur. Salston ve Figley (2003), günlük ve rutin beslenme alışkanlıkları ve zevk duyulan faaliyetlerde bulunma veya hobilerinin olmasının meslek personellerinin şahsi olarak alabilecekleri tedbirler içerisinde olduğunu dile getirmiştir. Hogancamp ile Figley (1983) yürüttükleri çalışmadaysa, travmaya maruziyeti yaşamış ve travmadan dolaylı olarak etkilenen mağdurun çevresinin yaşadıkları güçlüklerle başa çıkabilmelerinde işlevsel başa çıkma yöntemlerinin tanımlanması, gerekli durumlarda esneklik gösterebilme ve uzman destek hizmetlerinden faydalanmanın etkin hale getirilmesini önermektedirler. 
JPH, DECEMBER 2021, 6(3):421-432

Türkiye'de ise ilk yardım personellerinin kaygı, öfke, depresyon TSSB skoru oranlarının yüksek olduğunu bulgulayan çalışmalar da mevcuttur (Tokuç ve Turunç, 2011). Kahil (2016) tarafından yapılan bir çalışmada, profesyonel meslek gruplarının, gönüllü katılımcılara nazaran daha çok İTS belirtileri deneyimledikleri sonucuna varılmıştır. Ayrıca mesleği sürdürme yıllarına göre 11-15 yıldan beri yürüten katılımcıların 1-5 yıl arasında yürüten katılımcılara nazaran daha fazla travmatik stres belirtisi olduğu sonucuna varılmıştır. Travmatik yaşantıya sahip olan katılımcıların travmatik stres belirtilerinin öteki katılımcılara nazaran daha fazla olduğu sonucu açığa çıkmıştır (Kahil, 2016).

Yılmaz ve arkadaşlarının çalışmalarında, yardım faaliyetlerinde çalışanların olması muhtemel zorluklarla baş etmede kullanılan bireysel ve çevresel etmenlerin belirlemenin amaçlandığı araştırmada sabırlı, tolere edici olma, kararlılık ve yardımsever olma şeklindeki kişisel özelliklerin; aile fertlerinin verdiği desteğin başa etmeyi kolaylaştırdığı saptanmıştır (Yılmaz ve Şahin, 2007). Literatürde tramatik stres ile baş etme konusunda sosyal destek konusu önemli bir yer edinmektedir. Ayrıca sosyal desteğin travmaya adapte olmayı kolaylaştırdığı, travma sonrası semptomları minimuma indirdiği, travma sonrası stres bozukluğunun ortaya çıkmasını durdurduğu ve maruziyet yaşayan kişiyi ikincil travmalardan korumaktadır (Wong vd., 2006).

\section{SONUÇ}

Sekonder travma, travma ardından uyum çabalarını etkilemekte kaygı, depresyon, TSSB, madde bağımlılığı, alkol kullanımı gibi bozukluklara yol açmaktadır. Yardım çalışanlarında meydana gelen sekonder travmatik strese sebebiyet verebilecek olaylar saptanarak, riskli sınıflara uygun ve kişilere özgü rol modellerin geliştirilmesi gerekmektedir. Yaptıkları işten dolayı travmatik durumlara sürekli maruz kalabilme riski olan, fakat doğrudan travma mağduru olmadıklarından hem kendileri hem de danışmanlar tarafından çoğu zaman görmezden gelinebilen yardım çalışanlarının kişisel ve mesleki bilgi düzeylerinin arttırılmalıdır. Ayrıca travma ardındaki sürecin saptanması, travmatik durumların etkilerine karşı koruyucu ruh sağlığı uygulamasının planlanması ve uygun baş etme uygulamasının geliştirilmesi önem arz etmektedir.

Arama-kurtarma çalışanlarında ikincil travmatik stres ile alakalı riskli sınıflara yönelik çalışmaların yapılması ve gerekli tedbirlerin alınmasını sağlayarak çalışanların iş doyumunu arttıracak ve çalışma motivasyonunu yükseltecek kaliteli destek hizmetlerinin verilmesine olanak sağlayacaktır. Bugüne kadar yapılan çalışmaların hiçbiri doğrudan afet çalışanlarındaki 


\section{Journal of Pre-Hospital - Hastane Öncesi Dergisi}

JPH, DECEMBER 2021, 6(3):421-432

ikincil travmatik strese odaklanmamıştır. Gelecekteki araştırmalarda ikincil travmatik stresten konusuna daha fazla yer verilmelidir. Ülkemizde özellikle afetlerde (salgın hastalık, deprem, sel, tsunami vb.) görev alan afet yardım çalışanlarının ikincil travmatik stres açısından değerlendirilmesine yönelik surveyans çalışmalarının yapılması, alana yönelik farkındalığın artmasına yol açacak ve gerekli koruyucu hizmetlerin oluşturulmasına neden olacaktır.

\section{Yazar Katkıları}

$\mathrm{AD}$, GK ve $\mathrm{AD}$ çalışmanın tasarımı, $\mathrm{AD}$, GK literatür taraması ve $\mathrm{AD}$, GK makalenin yazımına katkı sunmuştur.

\section{Çıkar Çatışması}

Yazarlar çıkar çatışması beyan etmemektedir.

\section{Kaynakça}

Baird K., Kracen AC. (2006) Vicarious traumatization and secondary traumatic stress: A research synthesis. Couns Psychol Q, 19,181-188.

Bahadır, H. ve Uçku, R. (2018). Uluslararası acil durum veri tabanına göre Türkiye Cumhuriyeti tarihindeki afetler. Doğal Afetler ve Çevre Dergisi, 4(1), 28-33.

Balun, B. ve Yılmaz, K. (2019). Sürdürülebilir Bir Yönetim Paradigması: Ortopedik Engelli Bireylerin Afetlere Hazırlık Seviyeleri. Resilience, 3(1), 1-24.

Birinci, GG. ve Erden, G. (2016). Yardım Çalışanlarında Üstlenilmiş Travma, İkincil Travmatik Stres ve Tükenmişliğin Değerlendirilmesi. Turk Psikoloji Dergisi, 31(77).

Bell, H., Kulkarni, S. (2003). Organizational prevention of vicarious trauma. Families in Society: The Journal of Contemporary Human Services, 84, 463-470.

Berger, R. ve Gelkopf, M. (2011). An intervention for reducing secondary traumatization and improving professional self-efficacy in well baby clinic nurses following war and terror: A random control group trial. International journal of nursing studies, 48(5), 601-610.

Broby, N., Lassetter, JH., Williams, M. ve Winters, BA. (2018). Effective international medical disaster relief: a qualitative descriptive study. Prehospital and disaster medicine, 33(2), 119-126.

Carson, AJ., MacHale, S., Allen, K., Lawrie, SM., Dennis, M. ve House, A. (2000), Depression After Stroke and Lesion Location: A Systematic Review, Lancet, 8(356): 122126.

Dagan, SW., Ben-Porat, A. ve Itzhaky, H. (2016). Child protection workers dealing with child abuse: The contribution of personal, social and organizational resources to secondary traumatization. Child Abuse ve Neglect, 51, 203-211. 


\section{Journal of Pre-Hospital - Hastane Öncesi Dergisi}

JPH, DECEMBER 2021, 6(3):421-432

Doğan, T. ve Baker, E. (2014) Afetler Krizler Travmalar ve Psikolojik Yardım. Ankara. Türk Psikolojik Danışma ve Rehberlik Derneği.

Ertuğrul, B. ve Ünal, SD. (2019) Bir Vakıf Üniversitesi Sağlık Hizmetleri Meslek Yüksekokulunda Öğrenim Gören Öğrencilerin Genel Afete Hazırlıklı Olma İnanç Durumlarının Belirlenmesi. Afet ve Risk Dergisi, 3(1), 31-45.

Ewer, PL., Teesson, M., Sannibale, C., Roche, A., Mills, KL. (2014), The Prevalence And Correlates Of Secondary Traumatic Stress Among Alcohol And Other Drug Workers İn Australia. Drug Alcohol Rev, 34:252-258.

Figley, CR. (Ed.). (1995). Compassion fatigue: Coping with secondary traumatic stress disorder in those who treat the traumatized (No. 23). Psychology Press.

Hacıoğlu, M., Aker, T., Kutlar, T. ve Yaman, M. (2002). Deprem tipi travma sonrasında gelişen travma sonrası stres bozukluğu belirtileri alt tipleri. Düşünen Adam: Psikiyatri ve Nörolojik Bilimler Dergisi, 15, $4-15$.

Hogancamp, VE. ve Figley, CR. (1983). War: Bringing the battle home. Stress and the family/edited by Hamilton I. McCubbin ve Charles R. Fisley.

Işıkl1, S. ve Tüzün, Z. (2017). Afetlerin akut dönem psikolojik etkilerine yönelik psikososyal müdahale yaklaşımları.

Kahil, A. , Palabıyıkoğlu, N. (2018). İkincil Travmatik Stres . Psikiyatride Güncel Yaklaşımlar , 10 (1), 59-70 . Doi: 10.18863/pgy.336495

Kahil, A. (2016). Travmatik yaşantıları olan bireylere yardım davranışında bulunan profesyonel ve gönüllülerin ikincil travmatik stres düzeylerinin incelenmesi (Yüksek lisans tezi). Ankara, Ufuk Üniversitesi.

Kukuoğlu, A. (2018). Doğal Afetler Sonrası Yaşanan Travmalar ve Örnek Bir Psikoeğitim Programı. Afet ve Risk Dergisi, 1(1), 39-52.

Lock, S., Rubin, GJ., Murray, V., Rogers, MB., Amlôt, R. ve Williams, R. (2012). Secondary stressors and extreme events and disasters: a systematic review of primary research from 2010-2011.

Lee, K., Lee, SH., Park, T. ve Lee, JY. (2017). Stressors of Korean disaster relief team members during the Nepal earthquake dispatch: a consensual qualitative research analysis. Journal of Korean medical science, 32(3), 507-513.

Mao, X., Loke, AY., Fung, OWM. ve Hu, X. (2019). What it takes to be resilient: The views of disaster healthcare rescuers. International journal of disaster risk reduction, 36, 101112.

Mao, X., Fung, OWM., Hu, X. ve Loke, AY. (2018). Psychological impacts of disaster on rescue workers: A review of the literature. International Journal of Disaster Risk Reduction, 27, 602-617. 


\section{Journal of Pre-Hospital - Hastane Öncesi Dergisi}

JPH, DECEMBER 2021, 6(3):421-432

Moore, AL. (2004). Compassion fatigue, somatization, and trauma history: A study of disaster mental health professionals after the Oklahoma bombing. Alliant International University, San Francisco Bay.

Meadors, P. ve Lamson, A. (2008). Compassion fatigue and secondary traumatization: Provider self care on intensive care units for children. Journal of Pediatric Health Care, 22(1), 24-34.

Palabıyıkoğlu, R. ve Cesur, G. (2013). Yaşam sürecinde kriz ve krize müdahale. Sağlık Psikolojisi (Ed ÜH Okyayuz), 41-63.

McCann, IL. ve Pearlman, LA. (1990). Vicarious traumatization: A framework for understanding the psychological effects of working with victims. Journal of traumatic stress, 3(1), 131-149.

Rienks, SL. (2020). An exploration of child welfare caseworkers' experience of secondary trauma and strategies for coping. Child abuse ve neglect, 110, 104355.

Regehr, C. (2001), Crisis Debriefing Groups For Emergency Responders: Reviewing the Evidence. Brief Treatment and Crisis Intervention, 1(2), 87-100.

Salston MD., Figley CR. (2003) Secondary traumatic stress effects of working with survivors of criminal victimization. J Trauma Stress, 16:167-174.

Stamm, B. (2005). The professional quality of life scale: compassion satisfaction, burnout and compassion fatigue/secondary trauma scales. Institute of Rural Health. Sidan Press.

Sifaki-Pistolla, D., Chatzea, VE., Vlachaki, SA., Melidoniotis, E. ve Pistolla, G. (2017). Who is going to rescue the rescuers? Post-traumatic stress disorder among rescue workers operating in Greece during the European refugee crisis. Social psychiatry and psychiatric epidemiology, 52(1), 45-54.

Tominaga, Y., Goto, T., Shelby, J., Oshio, A., Nishi, D. ve Takahashi, S. (2020). Secondary trauma and posttraumatic growth among mental health clinicians involved in disaster relief activities following the 2011 Tohoku earthquake and tsunami in Japan. Counselling Psychology Quarterly, 33(4), 427-447.

Şavur, EY. ve Akdur, RTD. (2012). İnsani yardım çalışanlarının yardım arama davranışına ilişkin bir inceleme:Psikolojik belirtiler, psikolojik sağlamlık ve sosyal destek algısı' (Doctoral dissertation, Ankara Üniversitesi Sağlık Bilimleri Enstitüsü Disiplinlerarası Sosyal Psikiyatri Anabilim Dalı).

Tokuç, B. ve Turunç Y. (2011). Edirne'de ambulans çalışanlarının anksiyete, depresyon ve işe bağlı gerginlik düzeyleri. Galip Ekuklu Mesleki Sağlık ve Güvenlik Dergisi, 11 (42), 39-44.

Walker, A., McKune, A., Ferguson, S., Pyne, DB. ve Rattray, B. (2016). Chronic occupational exposures can influence the rate of PTSD and depressive disorders in first responders and military personnel. Extreme physiology ve medicine, 5(1), 1-12.

Williams, R., Ntontis, E., Alfadhli, K., Drury, J. ve Amlôt, R. (2021). A social model of secondary stressors in relation to disasters, major incidents and conflict: Implications for practice. International Journal of Disaster Risk Reduction, 102436. 


\section{Journal of Pre-Hospital - Hastane Öncesi Dergisi}

JPH, DECEMBER 2021, 6(3):421-432

Wong M, Looney E, Michaels J, Palesh O, Koopman CA. (2006).preliminary study of peritraumatic dissociation, social support, and coping in relation to posttraumatic stress symptoms for a parent's cancer. Psycho-Oncology,15(12),1093-1098.

Yılmaz B, Şahin NH. (2007).Arama-kurtarma çalışanlarında travma sonrasyı stres belirtileri ve travma sonrası büyüme. Türk Psikoloji Dergisi 2007;22:119-37.

Zara, A., ve İçöz, FJ. (2015). Türkiye'de Ruh sağlı̆̆ı alanında travma mağdurlarıyla çalışanlarda ikincil travmatik stres. Klinik Psikiyatri, 18, 15-23. 